\section{Oryx changes for 1999}

This is the last issue of Oryx in its current format. The January 1999 issue will follow the usual larger journal format $(276 \times 210 \mathrm{~mm})$. The change has allowed us to redesign Ory $x$ to give a fresh up-to-date look. It will also mean that we shall be able to publish more papers, while retaining the regular features that you value, and save on paper costs.

There will be changes in content as well, to reflect the modern trends in wildlife (or perhaps we should call it biodiversity) conservation. The issues have become much more complex. No longer is conservation just a matter of fencing off species-rich habitat, passing appropriate legislation or entering into international agreements. Conservationists are starting to come to terms with the shortcomings of traditional conservation and are having to devise new approaches to try to ensure that extant species continue to survive.

The aim of Oryx is to provide a comprehensive view of the conservation of wild species of fauna and flora world-wide. It welcomes succinct and up-to-date papers for rapid publication on all aspects of species conservation, focusing particularly on material that has potential to help improve conservation efforts and to enhance understanding of conservation needs. The journal invites manuscript submissions in several areas:

- Field research on the status and distribution of threatened species

- Reviews of the status and distribution of individual species or taxonomic groups

- Reviews of conservation policy at international, national and local levels

- Reviews of legislation relating to species and habitat conservation

- Planning for species and biodiversity conservation

- The working of international conservation conventions

- The nature and results of practical conservation initiatives by governmental and nongovernmental organizations

- Research on the sustainable use of wild species
- The history of conservation, including the role of key people, organizations and initiatives.

Case studies, when they are analytical and indicate why certain approaches were successful and how challenges were met, will be especially welcome.

In addition to the longer papers, Short Communications ( $<2000$ words) are invited on: research results that have important implications for conservation; wild species or habitats under immediate threat; new legislation, protected areas or conservation initiatives; and conservation gains and losses.

Some new conservation approaches are far from proven and are often the subject of debate. Oryx aims to encourage healthy and constructive dialogue in order to refine the approaches, and to promote a wider and deeper understanding of the problems and their causes. To this end, instead of the regular editorial I have been writing, we shall publish guest editorials from individuals representing all aspects of the conservation spectrum. News and Views will become Opinion, reflecting a change in emphasis, publishing contributions ( $<700$ words) to current conservation thinking, usually referring to material published in previous issues of the journal and probably dealing with controversial topics.

Briefly will continue to publish concise reports ( $<175$ words) on news of general conservation interest from a variety of sources. We want to extend the scope of this section so that it is truly global and we welcome contributions from individuals and organizations.

In a separate information section, we shall publish lists of meetings, details of grant availability, opportunities for research and requests for information.

Updated guidelines will be published in the January 1999 issue but are also available from The Editor, Oryx - The International Journal of Conservation, Winkfield, Station Road, Plumpton Green, East Sussex BN7 3BU, UK (e-mail: jacquim@pavilion.co.uk), to whom submissions should also be sent.

Jacqui Morris Editor

(C) $1998 \mathrm{FFI}$, Oryx, 32 (4) 